\title{
RIBAVIRIN INDUCED ANEMIA: A CROSS SECTIONAL STUDY AMONG PATIENTS WITH HEPATITIS C, VISITING OUT PATIENT DEPARTMENT OF A MAJOR PUBLIC SECTOR TERTIARY CARE HOSPITAL, KARACHI, PAKISTAN.
}

\author{
Zulfiqar Ali Shaikh', Javeria Shamim², Kelash Nankani ${ }^{3}$ \\ ${ }^{1}$ Professor, Community Medicine, Dow Medical College/DUHS, Karachi \\ ${ }^{2}$ Final Year Student, Dow Medical College/DUHS, Karachi \\ ${ }^{3}$ Professor, Physiology, Dow Medical College/DUHS, Karachi \\ Correspondence: Zulfiqar Ali Shaikh, Email: drzulfiqarshaikh@gmail.com
}

\begin{abstract}
Background: Hepatitis $\mathrm{C}$ is among one of the major global health issues; which may cause chronic liver disease, end stage liver disease, and hepatocellular carcinoma; subsequently requiring liver transplant. For HCV, standard treatment is a combination therapy of ribavirin and interferon for six months. Ribavirin fostered hemolysis is a major treatment-associated adverse effect. Our study aimed to assess ribavirin induced anemia among Hepatitis C patients visiting Civil Hospital, Karachi.

Methods: A hospital-based cross-sectional study which included 106 Hepatitis C patients, of 15-60 years' age, visiting CHK, a public sector tertiary care hospital, from October 2017 to January 2018 by using non-probability convenient sampling technique.

Results: Total 106 patients participated, $53(50.0 \%)$ were males and $53(50.0 \%)$ were females. Mean $( \pm S D)$ age was $37.05( \pm 10.793)$. Mean $( \pm S D)$ duration of ribavirin use was $3.03( \pm 1.523)$ months. Around $16.0 \%$ had ribavirin dose reduction. All of them experienced weakness, fatigue and light-headedness, $59.4 \%$ developed microcytic hypochromic anemia, $23.6 \%$ had severe anemia. Mean ( $\pm S D)$ hemoglobin level before the onset of treatment was $12.78( \pm 1.555)$. Mean hemoglobin level during treatment was $10.72 \mathrm{~g} / \mathrm{dL}$. Mean reduction in hemoglobin levels was $2.07 \mathrm{~g} / \mathrm{dL}$. The reduction in hemoglobin levels and the duration of therapy were correlated ( $p$-value $<0.05$ ). The severity of anemia was related to age of the patients ( $p$-value $<0.05$ ) but not with gender and RBC morphology.

Conclusion: Ribavirin induces anemia. The duration of ribavirin therapy and initial hemoglobin levels were related to the severity of anemia, significant enough to cause dose modification and subsequently suboptimal levels affecting efficacy. In return hemoglobin reduction, dose modification and age of the patient were also related.
\end{abstract}

Keywords: Hepatitis C, ribavirin, microcytic hypochromic anemia.

\section{Introduction}

Hepatitis C Virus (HCV) is among one of the major global health issues and significant public health burden, which when chronic, is responsible for causing CLD (chronic liver disease), ESLD (end stage liver disease) and hepatocellular carcinoma, leading to significant morbidity and mortality, subsequently requiring liver transplant.1,2 Numerous treatment strategies are available and a few are still in progress that adjust oral therapy along with optimum efficacy (>90\% cure rates), brief treatment duration (3-4 months), few contraindications and side effects comparable with treatment options available currently. 3 Primary prevention, without a potent vaccine, is safer blood transfusion and injection via sterile needles. In people with advanced liver disease, strategy for secondary prevention is screening for timely detection of infection and termination of alcohol consumption. 1 For HCV infection, standard treatment is a combination therapy of ribavirin and interferon for six months.4 Ribavirin fostered hemolysis is an important treatment-associated adverse effect, affecting the quality of life.5,6 Drug interaction, adverse effects and cost effectiveness are continuously challenging this regimen.2 Undoubtedly ribavirin plus interferon based therapies distinctly improves sustained viral response rates. Nearly every patient suffered anemia. 7

According to a study, $39 \%$ of patients developed severe anemia8, whose management required ribavirin dose adjustment and epoetin during ribavirin and interferon combination therapy.9 Another study suggested that when the dose of ribavirin was modified, the severity of anemia improved by $50 \% .1$ According to an American study, there was an association between the plasma ribavirin concentration and anemia. 11

This study was conducted to assess ribavirin induced 
anemia among Hepatitis $\mathrm{C}$ patients visiting Civil Hospital Karachi.

\section{Methodology}

This was a hospital-based, cross-sectional study. Data were collected from the diagnosed patients of Hepatitis C, visiting Hepatitis OPD of Civil Hospital Karachi, a public sector tertiary care hospital, prescribed a combination therapy of Ribavirin and interferon for six months, chosen according to the inclusion criteria of this study. The study was conducted from October 2017 to January 2018. The Sample size was decided to be 106 using non-probability convenient sampling technique. We included those patients who visited Hepatitis OPD of CHK, 15-60 years of age, willing to participate after taking informed consent, already diagnosed with Hepatitis $C$ and prescribed with ribavirin plus interferon, taking this therapy for $>15$ days but $<6$ months, had a $C B C$ reports with them before starting the treatment and another $\mathrm{CBC}$ report showing current hemoglobin levels and morphology were included. All those were excluded who refused to participate, had other forms of Hepatitis, were diagnosed but not investigated for genotype, in whom Ribavirin was contraindicated (hemoglobinopathies, etc.); those who completed six months ribavirin treatment, patients $<15$ years or $>60$ years; those who didn't have CBC report showing previous and current hemoglobin levels and RBC morphology or had decompensated HCV-CLD (ascites, splenomegaly or portal hypertension).

The questionnaire included the patients' demographic data, duration of diagnosis of Hepatitis, duration of ribavirin therapy, frequency and dosage of ribavirin, any change in the dosage of ribavirin therapy, alcohol intake, symptoms of anemia (shortness of breath, lightheadedness, weakness and fatigue, pale skin). Patients were inquired for their $\mathrm{CBC}$ reports for the hemoglobin levels before starting the treatment, current hemoglobin levels and RBC morphology. A self-administered, closed-ended questionnaire was used. All the participants were briefed regarding the objectives of this study and assured for their confidentiality and anonymity.

The data were analyzed by using Statistical Package for Social Sciences (SPSS) version 16.0. Frequency and percentages were calculated. Descriptive statistics were calculated for continuous data as Mean and standard deviation. Chi-Square test was applied to find the association of socio demographic variables with difference in hemoglobin levels during treatment, duration of ribavirin use with difference in hemoglobin levels during treatment. $P$ value less than 0.05 was considered statistically significant.

\section{Results}

A total of $106 \mathrm{HCV}$ patients were included in the study; among them $53(50.0 \%)$ were males and $53(50.0 \%)$ were females. Five participants $(4.7 \%)$ were of less than 20 years, $53(50.0 \%)$ of $20-40$ years age, while 48 $(45.3 \%)$ were $40-60$ years old.
Regarding the duration of diagnosis of Hepatitis C, 46 patients (43.4\%) had Hepatitis $C$ for less than 1 year, 32 $(30.2 \%)$ for $1-2$ years, $19(17.9 \%)$ for $2-3$ years, $7(6.6 \%)$ for $3-4$ years, while $2(1.9 \%)$ were living with Hepatitis C for $4-5$ years.

For the ribavirin use, 21 patients $(19.8 \%)$ were taking it for one month, 24 (22.6\%) for two months, 20 (18.9\%) for three months, $16(15.1 \%)$ for four months, $21(19.8 \%)$ for five months, while 4 (3.8\%) were taking ribavirin for six months along with interferon. Of them 17 patients $(16.0 \%)$ underwent dose modification because of worsening anemia.

Weakness, fatigue and light-headedness were reported by all the patients $(100 \%)$, breathlessness by 76 $(71.7 \%)$, paleness of skin color by $42(39.6 \%)$; while 63 $(59.4 \%)$ developed microcytic hypochromic anemia as indicated by their CBC (table 1).

Table 1: Frequency and Percentage of Clinical Data (hemoglobin according to $\mathrm{CBC}$ report)

\begin{tabular}{|l|l|l|l|}
\hline Variables & & Frequency & Percent (\%) \\
\hline RBC morphology & Normocytic & $43 / 106$ & $40.6 \%$ \\
& Normochromic & & $59.4 \%$ \\
& Microcytic & $63 / 106$ & \\
& Hypochromic & & \\
\hline Difference in hemoglobin & $1 \mathrm{~g} / \mathrm{dL}$ & $40 / 106$ & $37.7 \%$ \\
levels during treatment & $2 \mathrm{~g} / \mathrm{dL}$ & $31 / 106$ & $29.2 \%$ \\
& $3 \mathrm{~g} / \mathrm{dL}$ & $23 / 106$ & $21.7 \%$ \\
& $4 \mathrm{~g} / \mathrm{dL}$ & $9 / 106$ & $8.5 \%$ \\
\hline Hemoglobin level before & $5 \mathrm{~g} / \mathrm{dL}$ & $3 / 106$ & $2.8 \%$ \\
the onset of treatment & $10-11 \mathrm{~g} / \mathrm{dL}$ & $4 / 106$ & $3.8 \%$ \\
& $11-12 \mathrm{~g} / \mathrm{dL}$ & $21 / 106$ & $19.8 \%$ \\
& $12-13 \mathrm{~g} / \mathrm{dL}$ & $26 / 106$ & $24.5 \%$ \\
& $13-14 \mathrm{~g} / \mathrm{dL}$ & $18 / 106$ & $17.0 \%$ \\
& $14-15 \mathrm{~g} / \mathrm{dL}$ & $24 / 106$ & $22.6 \%$ \\
\hline Hemoglobin levels during & $15-16 \mathrm{~g} / \mathrm{dL}$ & $7 / 106$ & $6.6 \%$ \\
treatment & $16-17 \mathrm{~g} / \mathrm{dL}$ & $5 / 106$ & $4.7 \%$ \\
& $17-18 \mathrm{~g} / \mathrm{dL}$ & $1 / 106$ & $0.9 \%$ \\
\hline
\end{tabular}

While being on ribavirin therapy, 25/106 respondents $(23.6 \%)$ had severe anemia (hemoglobin $<10 \mathrm{~g} / \mathrm{dL}$ ). Mean $( \pm S D)$ duration of ribavirin use was $3.03( \pm 1.523)$ with the range 1-6 months. Mean ( $\pm S D$ ) hemoglobin level before the onset of treatment was $12.78( \pm 1.555)$. Mean hemoglobin level during treatment was $10.72 \mathrm{~g} / \mathrm{dL}$. Mean reduction in hemoglobin levels was $2.07 \mathrm{~g} / \mathrm{d}$ (table 2).

Table 2: Descriptive statistics of clinical data (mean and standard deviation)

\begin{tabular}{|l|l|l|}
\hline Variables & Mean & $\begin{array}{l}\text { Standard } \\
\text { Deviation }\end{array}$ \\
\hline $\begin{array}{l}\text { Difference in Hemoglobin Levels During } \\
\text { Treatment }(\mathrm{g} / \mathrm{dL})\end{array}$ & 2.0943 & 1.09134 \\
\hline Hemoglobin Before Start of Treatment $(\mathrm{g} / \mathrm{dL})$ & 12.7830 & 1.55536 \\
\hline Current Hemoglobin levels $(\mathrm{g} / \mathrm{dL})$ & 10.7264 & 1.72673 \\
\hline Duration of Diagnosis of Hepatitis C (years) & 1.9340 & 1.02603 \\
\hline How Long Ribavirin use (months) & 3.0377 & 1.52393 \\
\hline Age (years) & 37.0566 & 10.79315 \\
\hline
\end{tabular}

The reduction in Hemoglobin levels and the duration of therapy were correlated ( $p$-value $<0.05$ ) (table 3 , figure 1) 
Table 3: Difference in Hemoglobin Level with the Duration of Therapy (using Chi-square test)

\begin{tabular}{|c|c|c|c|c|c|}
\hline Duration of Ribavirin Use & \multicolumn{5}{|c|}{ Difference in Hemoglobin levels } \\
\hline & $1 \mathrm{~g} / \mathrm{dL}$ & $2 \mathrm{~g} / \mathrm{dL}$ & $3 \mathrm{~g} / \mathrm{dL}$ & $4 \mathrm{~g} / \mathrm{dL}$ & $5 \mathrm{~g} / \mathrm{dL}$ \\
\hline 1 month & 20 & 01 & 00 & 00 & 00 \\
\hline 2 months & 13 & 08 & 03 & 00 & 00 \\
\hline 3 months & 06 & 12 & 02 & 00 & 00 \\
\hline 4 months & 00 & 07 & 07 & 02 & 00 \\
\hline 5 months & 01 & 02 & 11 & 05 & 02 \\
\hline 6 months & 00 & 01 & 00 & 02 & 01 \\
\hline
\end{tabular}

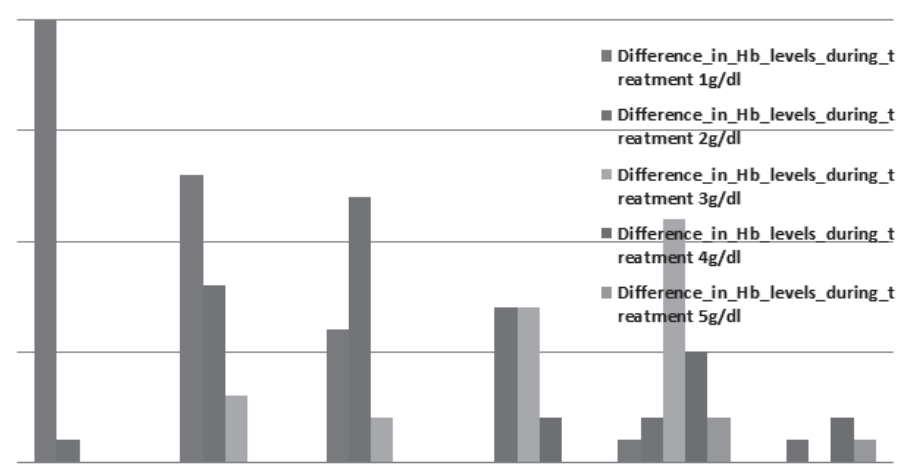

Figure I: Duration of Therapy \& Difference in Hemoglobin Levels ( $x$-axis representing the duration of therapy, whereas $y$-axis representing number of patients with their respective difference in hemoglobin levels as mentioned with specified colors in the graph)

There was statistically significant relationship between duration of ribavirin therapy and reduction in hemoglobin levels ( $p$-value $=0.000)$. There was no significant relationship between gender and difference in hemoglobin levels during therapy ( $p$-value $=0.697$ ). The reduction in hemoglobin level had significant relationship with age $(p$-value $=0.013)$. Hemoglobin reduction and ribavirin dose reduction were related ( $p$ value $=0.000$ ). The duration of ribavirin use and microcytic hypochromic anemia were not significantly related ( $p$-value $=0.576)$. Severity of anemia with initial hemoglobin levels, current hemoglobin levels with RBC morphology were related and statistically significant $(p-$ value $=0.000$ ).

\section{Discussion}

The treatment adequacy of HCV relies upon the compliance to the optimum dose and duration of therapy. The treatment efficacy reduces whenever there comes the factor of non-compliance/dose modification/drug withdrawal due to rapidly worsening adverse effects of combination therapy. Anemia is one of them as ribavirin induces hemolysis and erythropoiesis being directly inhibited by interferon.12 The reduction in hemoglobin level and the resultant anemia varies among individuals depending upon the duration of therapy.13,14 Some patients remained asymptomatic until marked reduction in hemoglobin levels.

According to this study, most of the patients $(50.0 \%)$ were 20-40 years of age. Majority had Hepatitis for less than 1 year $(43.4 \%)$. It was observed that $23.6 \%$ had severe anemia, maximum hemoglobin reduction was in second month of therapy $(22.6 \%)$ with mean maximum decrease of $1.583 \mathrm{~g} / \mathrm{dL}$ and $16.0 \%$ had ribavirin dose reduction which was in contrast to another Pakistani study showing maximum hemoglobin reduction was in first month of therapy with the mean maximum decrease of $2.05 \mathrm{~g} / \mathrm{dL} 12$. Also contrary to an Italian study showing marked reduction in hemoglobin was during first month. 5 It was also supported by a study conducted in Canada and Netherland.15 Another study showed 13\% patients needed dose modification due to worsening anemia.16,17

During therapy, hemoglobin levels kept on decreasing throughout six months which was contrary to a study showing hemoglobin reduction till four months and then improved.18

According to our study, weakness, fatigue and lightheadedness were experienced by all of the patients, breathlessness by $71.7 \%$ and $39.6 \%$ had paleness of skin color due to increasing severity of anemia and decreasing hemoglobin levels. Whereas $59.4 \%$ patients even had microcytic hypochromic anemia evident by their complete blood picture.

Reduction in hemoglobin levels was not influenced by gender but with age which was in contrast to another study that showed male gender comparatively had marked difference in hemoglobin levels. 19

Another study depicted severity of anemia was related with female gender, body weight and old age.8 While a Japanese study manifested body weight statistically related with reduction in hemoglobin levels. 20

\section{Conclusion}

Ribavirin induces anemia. The duration of ribavirin therapy and initial hemoglobin levels were related to the severity of anemia, significant enough to cause dose modification and subsequently suboptimal levels affecting efficacy. In return hemoglobin reduction and dose modification were also related. The severity of anemia was also related to age of the patients but not with gender.

\section{Recommendations}

Further studies are recommended to obtain data not only from other public sector tertiary care hospitals but also from private sector.

\section{Acknowledgment}

We are grateful to our study participants.

\section{Source of funding}

None

Conflicts of interest

There were no conflicts of interest.

\section{References}

1. Hanafiah KM, Groeger J, Flaxman AD, Wiersma ST. Global epidemiology of hepatitis C virus infection: New estimates of age-specific antibody to HCV seroprevalence. Hepatology 2013;57(4):1333-42. 
2. Osinusi A, Meissner EG and Kottilil S. Efficacy of Sofosbuvir and Ribavirin for treatment of Hepatitis C Genotype-1 in an Inner City Population: Virus and Host Factors that Predict Relapse. JAMA. 2013 Aug 28; 310(8):804-11.

3. Bruggmann P, Berg T, Ovrehus ALH, Moreno C, Mello CEB, Roudot-Thoraval F, et al. Historical epidemiology of hepatitis $\mathrm{C}$ virus (HCV) in selected countries. JVH 2014; 21(1):5-33.

4. Quiles-Perez R, Munoz-de-Rueda $P$, Maldonado AM, Martin-Alvarez A, Quer J, Salmeron J. Effects of ribavirin monotherapy on the viral population in patients with chronic hepatitis $C$ genotype 1: direct sequencing and pyrosequencing of the HCV regions. Journal of Medical Virology 2014;86(11):1886-97.

5. Ronzoni L, Aghemo A, Rumi MG, Prati G, Colancecco A, Porretti L, et al. Ribavirin suppresses erythroid differentiation and proliferation in chronic hepatitis $\mathrm{C}$ patients. JVH. 2014; 21(6):416-23.

6. Soota K, Maliakkal B. Ribavirin induced hemolysis: A novel mechanism of action against chronic hepatitis $C$ virus infection. World Journal of Gastroenterology 2014; 20(43):16184-90.

7. Pradat P, Virlogeux V, Gagnieu MC, Zoulim F, Bailly F. Ribavirin at the Era of Novel Direct Antiviral Agents for the Treatment of Hepatitis C Virus Infection: Relevance of Pharmacological Monitoring. Advances in Hepatology. 2014;Article ID 493087

8. Hung $\mathrm{CH}$, Lee CM, Lu SN, Wang JH, Chen $\mathrm{CH}$, $\mathrm{Hu} \mathrm{TH}$, et al. Anemia associated with antiviral therapy in chronic hepatitis $\mathrm{C}$ : incidence, risk factors, and impact on treatment response. Liver International. 2006;26(9):1079-86.

9. Romero-Gomez M, Berenguer M, Molina E, Calleja JL. Management of anemia induced by triple therapy in patients with chronic hepatitis $\mathrm{C}$ : challenges, opportunities and recommendations. Journal of Hepatology 2013;59(6):1323-30.

10. Wu LS, Jimmerson LC, MacBraynr CE, Kiser JJ, D'Argenio DZ. Modeling ribavirin-induced anemia in patients with chronic hepatitis $C$ virus. CPT: Pharmacometrics \& Systems Pharmacology 2016;5(2):65-73.

11. Rower JE, Meissner EG, Jimmerson LC, Osinusi A, Sims Z, Peterson T, et al. Serum and cellular ribavirin pharmacokinetic and concentration-effect analysis in HCV patients receiving sofosbuvir plus ribavirin. J Antimicrob Chemother 2015;70(8):2322-29.

12. Jadoon SA, Ahmed A, Jadoon HA. Effect of standard interferon and ribavirin on hemoglobin level in hepatitis-C patients. Journal of Ayub Med College Abbottabad 2014;26(4):510-12.

13. Pontali E, Angeli E, Cattelan AM, Maida I, Nasta
$P$, Verucchi $G$, et al. Cytopenias during treatment of HIV/HCV co-infection with pegylated interferon and ribavirin : safety analysis of the OPERA study. Antiviral Therapy 2015;20(1):3948.

14. Jimmerson LC, Clayton CW, MaWhinney S, Meissner EG, Sims Z, Kottilil S, et al. Effects of Ribavirin/Sofosbuvir treatment and ITPA phenotypes on endogenous purines. Antiviral Research 2017;138:79-85.

15. Maan R, van der Meer AJ, Brouwer WP, Plompen EP, sonneveld MJ, Roomer R, et al. ITPA polymorphisms are associated with hematological side effects during antiviral therapy for chronic HCV infection. PLoS One 2015;10(10):e0139317.

16. Fried MW, Shiffman ML, Rajender Reddy K. Peginterferon alfa-2a plus ribavirin for chronic hepatitis $C$ virus infection. The New England Journal of Medicine 2002;347(13):975-82.

17. Manns MP, McHutchison JG, Gordon SC. Peginterferon alfa-2b plus ribavirin compared with interferon alfa-2b plus ribavirin for initial treatment of chronic hepatitis $\mathrm{C}$ : a randomised trial. The Lancet2001;358(9286):958-65.

18. Siddiq S, Batool F, Malik K. Hematological side effects of pegylated interferon alpha $2 a$ and ribavirin therapy at Sheikh Khailifa Bin Zaid Hospital, Rawalakot, Pakistan. Rawal Medical Journal 2016;41(3):280-82.

19. Rafique G, Bukhsh A, Gul A, Khiljee S, Ashraf M, Omer MO. Hematological adverse effects and efficacy monitoring in chronic hepatitis C patients treated with interferon and ribavirin combination therapy. Pakistan Journal of Pharmaceutical Sciences 2017;30(1):11-16.

20. Morio K, Imamura M, Kawakami Y, Nakahara T, Nagaoki Y, Kawaoka T, et al. ITPA polymorphism effects on decrease of hemoglobin during sofosbuvir and ribavirin combination treatment for chronic hepatitis C. Journal of Gastroenterology 2017;52(6):746-53. 